\title{
TLR-Directed Cationic Lipid-DNA Complex JVRS-100
}

National Cancer Institute

\section{Source}

National Cancer Institute. TLR-Directed Cationic Lipid-DNA Complex JVRS-100. NCI

Thesaurus. Code C82353.

A cationic lipid DNA complex (CLDC) consisting of DOTIM/cholesterol liposomes and plasmid DNA, containing immunostimulatory CpG and non-CpG motifs, with potential immunostimulating and antineoplastic activities. Upon systemic administration, TLRdirected cationic lipid-DNA complex JVRS-100 enters dendritic cells (DCs) and macrophages; immunostimulatory DNA binds to and activates Toll-like receptors (TLRs), which may result in the generation of anti-tumor natural killer (NK) cell and T-cell responses by the innate immune system. In addition, as a vaccine adjuvant, this agent may induce a strong cytotoxic T-lymphocyte $(C T L)$ response to co-administered antigen. 